\title{
Circulating cell-derived microparticles in patients with minimally symptomatic obstructive sleep apnoea
}

\author{
L. Ayers*, B. Ferry*, S. Craig" ${ }^{\#}$ D. Nicoll ${ }^{\#}$, J.R. Stradling ${ }^{\#}$ and M. Kohler ${ }^{\#, 9}$
}

ABSTRACT: Moderate-severe obstructive sleep apnoea (OSA) has been associated with several pro-atherogenic mechanisms and increased cardiovascular risk, but it is not known if minimally symptomatic OSA has similar effects. Circulating cell-derived microparticles have been shown to have pro-inflammatory, pro-coagulant and endothelial function-impairing effects, as well as to predict subclinical atherosclerosis and cardiovascular risk.

In 57 patients with minimally symptomatic OSA, and 15 closely matched control subjects without OSA, AnnexinV-positive, platelet-, leukocyte- and endothelial cell-derived microparticles were measured by flow cytometry.

In patients with OSA, median (interquartile range) levels of AnnexinV-positive microparticles were significantly elevated compared with control subjects: $2,586(1,566-3,964) \mu L^{-1}$ versus 1,206 (474-2,501) $\mu \mathrm{L}^{-1}$, respectively. Levels of platelet-derived and leukocyte-derived microparticles were also significantly higher in patients with OSA $\left(2,267(1,102-3,592) \mu \mathrm{L}^{-1}\right.$ and $20(14-31) \mu \mathrm{L}^{-1}$, respectively) compared with control subjects (925 (328-2,068) $\mu \mathrm{L}^{-1}$ and 15 (5-23) $\mu \mathrm{L}^{-1}$, respectively). Endothelial cell-derived microparticle levels were similar in patients with OSA compared with control subjects (13 (8-25) $\mu \mathrm{L}^{-1}$ versus $\left.11(6-17) \mu \mathrm{L}^{-1}\right)$.

In patients with minimally symptomatic obstructive sleep apnoea, levels of AnnexinV-positive, platelet- and leukocyte-derived microparticles are elevated when compared with closely matched control subjects without obstructive sleep apnoea. These findings suggest that these patients may be at increased cardiovascular risk, despite being minimally symptomatic.

\section{KEYWORDS: Atherosclerosis, cardiovascular risk, microparticles, obstructive sleep apnoea}

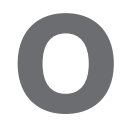

bstructive sleep apnoea (OSA) is characterised by repetitive apnoeas/hypopnoeas during sleep, which are associated with oxygen desaturations and arousals from sleep. It has been estimated that $2-4 \%$ of the adult population in Western countries suffer from symptomatic OSA, and it is becoming more prevalent as the average population body weight rises [1]. The prevalence of minimally symptomatic OSA among middle-aged adults has been shown to be as high as $26 \%$ [1], making OSA one of the most frequent disorders, and of major epidemiologic interest.

Cross-sectional and prospective studies have implicated OSA as an important potential causal factor in the development of cardiovascular disease [2]. The mechanisms underlying the association between OSA and cardiovascular disease are currently not fully understood. Multiple causal factors leading to vessel wall damage and atherosclerotic plaques have been proposed, including reflex sympathetic activation, consequent increases in blood pressure, endothelial dysfunction, activation of platelets, systemic inflammation, reactive oxygen species and hypoxia-induced apoptosis of endothelial cells [3-6].

Microparticles (MPs) circulating in peripheral blood originate from the plasma membrane of diverse activated or apoptotic cells of platelet, leukocyte and endothelial origin, and are involved in the pathogenesis of vascular inflammation, thrombosis, endothelial dysfunction and atherosclerosis [7, 8]. Plasma levels of MPs have been shown to be elevated in patients with cardiovascular risk factors [9, 10], have been shown to predict subclinical atherosclerosis burden in asymptomatic subjects [11], and appear to be a predictor of the recurrence of myocardial infarction or death in patients with acute coronary syndromes [12]. As a result, there is growing interest in early detection of these novel

\section{AFFILIATIONS}

*Dept of Clinical Immunology, and

\# Oxford Centre for Respiratory Medicine, Churchill Hospital, Oxford, UK.

"Pulmonary Division, University Hospital of Zurich,

Zurich, Switzerland.

CORRESPONDENCE

M. Kohler

Sleep Unit, Pulmonary Division University Hospital of Zurich

Raemistrasse 100

8091 Zurich

Switzerland

Fax: 41442554451

E-mail: malcolm.k@bluewin.ch

Received:

July 172008

Accepted after revision:

November 062008

SUPPORT STATEMENT

M. Kohler is a recipient of a

European Respiratory Society

(No 118) and University of Zurich

research fellowship.

STATEMENT OF INTEREST

A statement of interest for

this study can be found at www.erj.ersjournals.com/misc/ statements.shtml 
measures of cardiovascular risk with the anticipation that an intervention could reduce their levels and, thus, benefit patients who are at increased risk for future cardiovascular events.

However, there are no studies measuring circulating MPs in patients with highly prevalent minimally symptomatic OSA, and none investigating diverse subgroups of MPs originating from platelets, leukocytes and endothelial cells in patients with OSA.

To explore this novel hypothesis regarding the mechanism of vascular damage in OSA, a cross-sectional study measuring circulating cell-derived MPs was performed in patients with minimally symptomatic OSA, and compared with a closely matched control group.

\section{METHODS}

\section{Patients}

Patients with possible OSA were referred to the Oxford Sleep Unit, Oxford Centre for Respiratory Medicine (Oxford, UK), by general practitioners, ear, nose and throat surgeons, or other hospital consultants, because of severe snoring or witnessed apnoeas. Patients were eligible for the study if they were aged $45-75 \mathrm{yrs}$, had proven OSA with a severity defined as $>7.5$ oxygen desaturations of $>4 \%$ per hour (oxygen desaturation index (ODI) $>7.5$ events $\cdot \mathrm{h}^{-1}$ ), and no history of excessive daytime sleepiness or any other daytime symptom of OSA (such as tiredness or fatigue) which would have justified a trial of continuous positive airway pressure therapy. The level of symptoms was assessed at clinical interview, with no specific upper threshold for the Epworth sleepiness scale (ESS) value to exclude entry. All eligible patients were offered participation in the study.

Control subjects were mainly identified and recruited from a general practitioner's database and were eligible for the study if they were aged 45-75 yrs with no history of OSA, had $<5$ oxygen desaturations of $>4 \%$ per hour (ODI $<5$ events $\cdot h^{-1}$ ) and an apnoea/hypopnoea index $<5$ events $\cdot h^{-1}$. Control subjects were matched to patients with OSA for sex, age, body mass index (BMI), waist to hip ratio and cardiovascular comorbidities. The study was approved by the Oxford research ethics committee (REC number 05/Q1604/159), and written informed consent was obtained from all participants.

\section{Sleep study and assessment of sleepiness}

In patients, OSA was diagnosed from a one-night in-hospital respiratory polygraphic sleep study. Patients' body movements, heart rate and pulse transit time (PTT) changes were recorded as measures of arousal from sleep. Pulse oximetry, snoring and increases in the respiratory swing in PTT were used as markers of breathing pattern and respiratory effort (Win-Visi monitoring system; Stowood Scientific Instruments, Oxford, UK) as previously described and validated [13, 14].

The results of the sleep study were scored automatically, with manual review to ensure accuracy of the data. OSA was diagnosed from a review of all data, and severity was quantified as the number of oxygen desaturations $>4 \%$ per hour of study (ODI). In control subjects, OSA was excluded by home sleep studies using the apnoeaLink ${ }^{\mathrm{TM}}$ device (MAP medicine technology; ResMed, Martinsried, Germany). This device records the patient's nasal respiratory pressure signal and finger oximetry during sleep; it has been validated as an accurate instrument for the detection of snoring, apnoea/ hypopnoea and oxygen desaturations [15]. The results of the sleep study were scored automatically with dedicated software (MAP medicine technology; ResMed), with manual review to ensure accuracy of the data. Apnoeas were defined as a cessation of airflow lasting $>10 \mathrm{~s}$, and hypopnoeas as a reduction in airflow of $\geqslant 50 \%$ lasting $>10 \mathrm{~s}$, associated with a drop in oxygen saturation of $>4 \%$.

Comparisons of measurements of the ODI in seven control subjects on two different nights by both sleep study methods (Win-Visi monitoring system and apnoeaLink ${ }^{\mathrm{TM}}$ ) revealed a small and nonsignificant bias (mean difference in ODI was -0.29 desaturations $\cdot \mathrm{h}^{-1} ; \mathrm{p}=0.72$ ); all seven subjects had an ODI of $<5$ events $\cdot h^{-1}$ in both sleep studies.

Subjective sleepiness was assessed using the ESS, which assesses the tendency to fall asleep during eight typical daytime situations [16]. Objective sleepiness was measured with one sleep resistance challenge (Osler test), which tests the ability to stay awake in a darkened and sound isolated room [17].

\section{Cardiovascular risk score}

A cardiovascular risk score (Framingham index) was used to objectively assess an individual's 5-yr risk of death due to cardiovascular events [18]. The risk score is based on 11 factors, including: age, sex, systolic blood pressure, serum total cholesterol concentration, height, serum creatinine concentration, cigarette smoking, diabetes, left ventricular hypertrophy (evaluated by resting ECG; Sokolow-Lyon index; $\mathrm{S}_{\mathrm{V} 1}+\mathrm{R}_{\mathrm{V} 5 / \mathrm{V} 6}$ $>3.5 \mathrm{mV}$ ), history of stroke and myocardial infarction. The risk score is an integer, with points added for each factor according to its association with risk. The sum score, and the corresponding risk of a fatal cardiovascular event within 5 yrs, were derived from individual patient data according to Pocock et al. [18].

Office blood pressure was measured in the sitting position after a period of rest for 5 min with a standard digital automatic monitor (Omron Healthcare Company, Kyoto, Japan). The mean value of three readings was used for analysis.

\section{Measurement of MPs}

MPs were measured by flow cytometry as previously described by BIRO et al. [19] and blind of the patient group.

Briefly, blood was drawn from fasting participants in the morning between 09:00 $\mathrm{h}$ and 10:00 $\mathrm{h}$ using a $19 \mathrm{G}$ needle. Within $1 \mathrm{~min}$ of the blood being taken, the tubes were centrifuged at $1,550 \times g$ for $20 \mathrm{~min}$ at $20^{\circ} \mathrm{C}$, in order to produce platelet-free plasma. $250 \mu \mathrm{L}$ of plasma was aliquoted, frozen immediately and stored at $-80^{\circ} \mathrm{C}$.

The $250-\mu \mathrm{L}$ samples were thawed on melting ice for $1 \mathrm{~h}$ and then spun at $18,000 \times g$ for $30 \mathrm{~min}$ at $20^{\circ} \mathrm{C}$. $225 \mu \mathrm{L}$ of supernatant was removed, and $225 \mu \mathrm{L}$ of PBS-citrate, $0.32 \%$, was added. The samples were spun again at $18,000 \times g$ for $30 \mathrm{~min}$ at $20^{\circ} \mathrm{C}$. $225 \mu \mathrm{L}$ of supernatant was again removed and replaced with $75 \mu \mathrm{L}$ of PBS-citrate $0.32 \%$. The diluted monoclonal antibodies (MAbs) were spun again at $18,000 \times g$ for $5 \mathrm{~min}$, to remove MAb-MAb complexes, and the supernatant transferred to a fresh tube. 
Annexin-V fluoresceinisothiocyanate (AnnV-FITC; Becton Dickinson, Oxford, UK) was used to stain all phosphatidylserine-positive MPs of endothelial, platelet and lymphocyte origin. AnnV-FITC in the absence of calcium was used as a negative control.

CD31-phycoerythrin (CD31-PE), CD41-PE-Cy5 (Becton Dickinson) were used to differentiate between platelet-derived MPs (PMPs; CD31+CD41+) and endothelial cell-derived MPs (EMPs; CD31+CD41-). CD45-allophycocyanin (CD45-APC; Becton Dickinson) was used as a marker for lymphocytederived MPs (LMPs; CD45+). Appropriate PE, PE-Cy5 and $\mathrm{APC}$ isotypes were used as negative controls.

Each sample was stained in two tubes, the first containing AnnV-FITC, CD31-PE and CD41-PE-Cy5 to detect PMPs and EMPs, the second containing AnnV-FITC and CD45-APC, to detect LMPs.

Diluted AnnV-FITC or MAbs $(5 \mu \mathrm{L})$ were added to PBScalcium $2.5 \mathrm{mmol} \cdot \mathrm{L}^{-1}$ to make up a total volume of $50 \mu \mathrm{L}$. $10 \mu \mathrm{L}$ of sample was incubated with the appropriate MAbs for $30 \mathrm{~min}$ at room temperature, protected from light. After the incubation, $900 \mu \mathrm{L}$ of PBS-calcium was added.

\section{Acquisition of samples}

Samples were acquired using FACSCalibur ${ }^{\circledR}$ (Becton Dickinson). Compensations were checked by acquiring single colour stained tubes. The MP gate was checked at each run by acquiring a tube containing $10 \mu \mathrm{L}$ of MPs and $5 \mu \mathrm{L}$ of $1 / 1,000$ dilution of $1 \mu \mathrm{M}$ beads (Sigma-Aldrich L-2778, St Louis, MO, USA) in $950 \mu \mathrm{L}$ of PBS-calcium.

\section{Data analysis}

Data are expressed as mean $\pm S D$ if data were normally distributed, and as median (interquartile range) if data were not normally distributed. Differences between the OSA and the control group in patient characteristics and MPs were compared by independent t-tests if data were normally distributed, or by the Mann-Whitney U-test if data were not normally distributed. For comparison of frequencies, Chisquared test of independence was used. Spearman's rank test was used for correlation analysis. A p-value $<0.05$ was considered statistically significant.

\section{RESULTS}

\section{Subject characteristics}

A total of 57 patients with minimally symptomatic OSA and 15 control subjects without OSA were recruited. Control subjects were well matched for age, sex, BMI, waist to hip ratio and cardiovascular risk profile. There was no statistically significant difference in prescribed antihypertensive and cholesterolor glucose-lowering medications between the two groups. As would be expected, patients with OSA had a higher ODI, a greater neck circumference, and tended to have a higher ESS, although objective sleepiness assessed by the Osler test was similar in the two groups (table 1).

\section{AnnexinV-positive MPs}

The median level of AnnexinV+ MPs was significantly higher in patients with minimally symptomatic OSA $(2,586(1,566-$ $\left.3,964) \mu \mathrm{L}^{-1}\right)$ than in matched control subjects $(1,206$ (474$\left.2,501) \mu \mathrm{L}^{-1} ; \mathrm{p}=0.007\right)$, as illustrated in figure 1 .

\section{TABLE 1 Patient characteristics}

Patients with OSA

\section{Subjects $n$}

Age yrs

BMI $\mathrm{kg} \cdot \mathrm{m}^{-2}$

Waist/hip circumference ratio

Neck circumference $\mathrm{cm}$

Females \%

Current smokers \%

Ex-smokers ${ }^{\#} \%$

Hypertension ${ }^{\#} \%$

Mean BP $\mathrm{mmHg}$

Antihypertensive medication \%

Total cholesterol $\mathrm{mmol} \cdot \mathrm{L}^{-1}$

Statin medication \%

Diabetes ${ }^{\#} \%$

Fasting glucose $\mathrm{mmol} \cdot \mathrm{L}^{-1}$

CAD ${ }^{\#} \%$

Cardiovascular risk score $\%$

Oxygen saturation dips $>4 \%$ per hour of sleep

ESS

Osler test min

57
$56.6 \pm 6.6$
$32.0 \pm 5.3$
$0.97 \pm 0.05$
$43.3 \pm 3.6$
10.5
15.8
35.1
40.4
$102.3 \pm 11$
40.4
$5.5 \pm 1.1$
30.9
15.8
$5.9 \pm 1.3$
10.5
$2.4 \pm 3.83$
$23.1 \pm 15.0$
$8.3 \pm 3.8$
$32.9 \pm 10.7$

Controls

15

$58.1 \pm 6.9$

$31.7 \pm 2.6$

$0.97 \pm 0.06$

$40.8 \pm 3.0$

13.3

13.3

33.3

46.7

$98.1 \pm 10.2$

46.7

$5.2 \pm 1.2$

33.3

6.7

$6.0 \pm 0.8$

13.3

$3.0 \pm 4.6$

$2.9 \pm 1.1$

$6.5 \pm 3.4$

$35.2 \pm 10.2$ p-value

0.42
0.81
0.93
0.02
0.76
0.81
0.90
0.66
0.20
0.66
0.40
0.86
0.36
0.82
0.76
0.66
0.0001
0.09
0.45

Data are presented as mean \pm SD, unless otherwise stated. OSA: obstructive sleep apnoea; BMI: body mass index; BP: blood pressure; CAD: coronary artery disease;

ESS: Epworth Sleepiness Score. ${ }^{*}$ : defined by medical history; ${ }^{\prime}$ : estimates the risk of death (in per cent) in the next 5 yrs due to a cardiovascular event. 


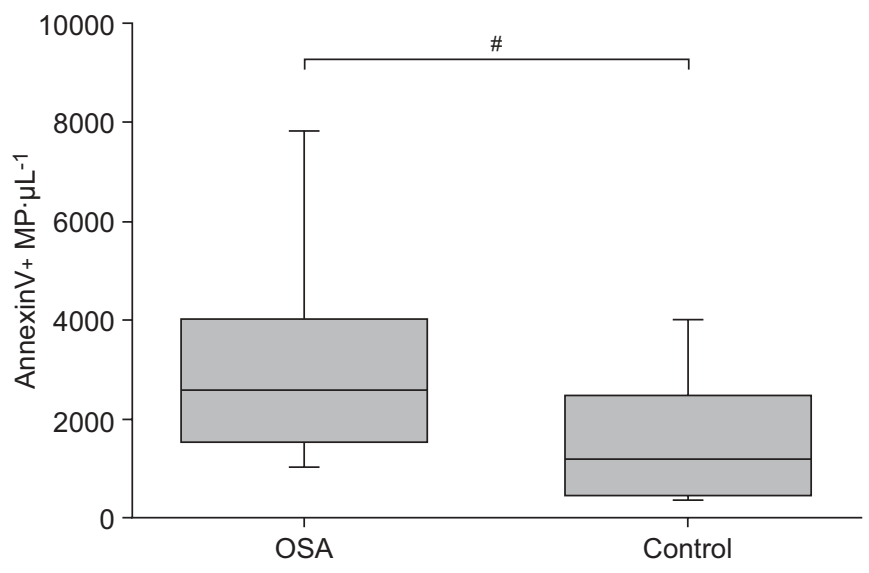

FIGURE 1. AnnexinV-positive microparticle (MP) levels, as assessed by flow cytometry, were significantly higher in patients with minimally symptomatic obstructive sleep apnoea (OSA) than in control subjects without OSA. Box and whisker plots represent medians, interquartile ranges and 10th and 90th percentiles. \#: $p=0.007$.

There was no correlation between the level of AnnexinV+ MPs and ODI $(\mathrm{r}=0.12, \mathrm{p}=0.31)$.

\section{CD31+CD41+ PMPs}

Patients with OSA had significantly higher median levels of PMPs $\left(2,267(1,102-3,592) \mu \mathrm{L}^{-1}\right)$ than matched control subjects without OSA (925 (328-2,068) $\mu \mathrm{L}^{-1} ; \mathrm{p}=0.009$; fig. 2). There was no correlation between the level of PMPs and ODI $(r=0.09$, $\mathrm{p}=0.43)$.

\section{CD31+CD41- EMPs}

Levels of peripheral blood EMPs were slightly higher in patients with OSA $\left(13(8-25) \mu \mathrm{L}^{-1}\right)$ compared with control subjects (11 (6-17) $\left.\mu \mathrm{L}^{-1}\right)$, although this difference did not reach statistical significance ( $p=0.21$; fig. 3 ). There was no correlation between the level of EMPs and ODI $(r=0.12, p=0.32)$.

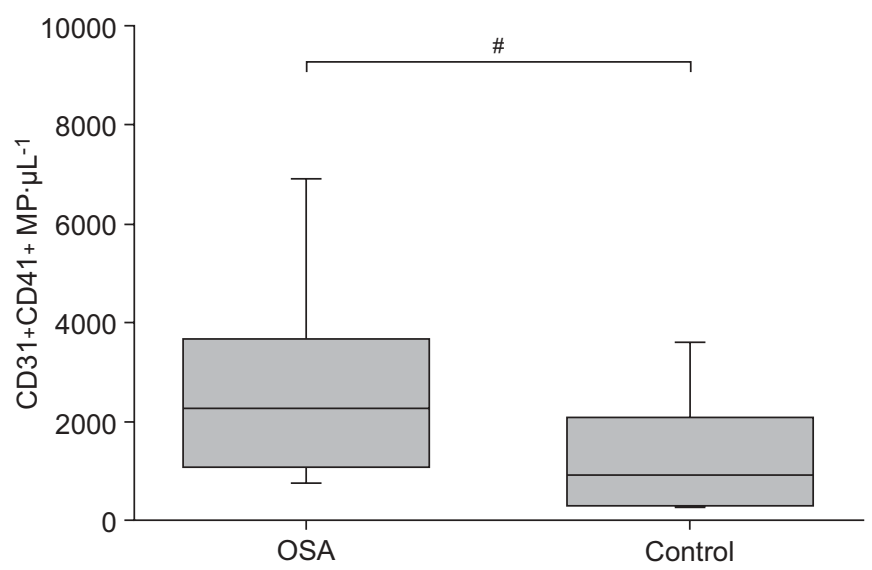

FIGURE 2. CD31+CD41+ platelet-derived microparticle (MP) levels were significantly higher in patients with minimally symptomatic obstructive sleep apnoea (OSA) than in the control group without OSA. Box and whisker plots represent medians, interquartile ranges and 10th and 90th percentiles. ${ }^{*}: p=0.009$.

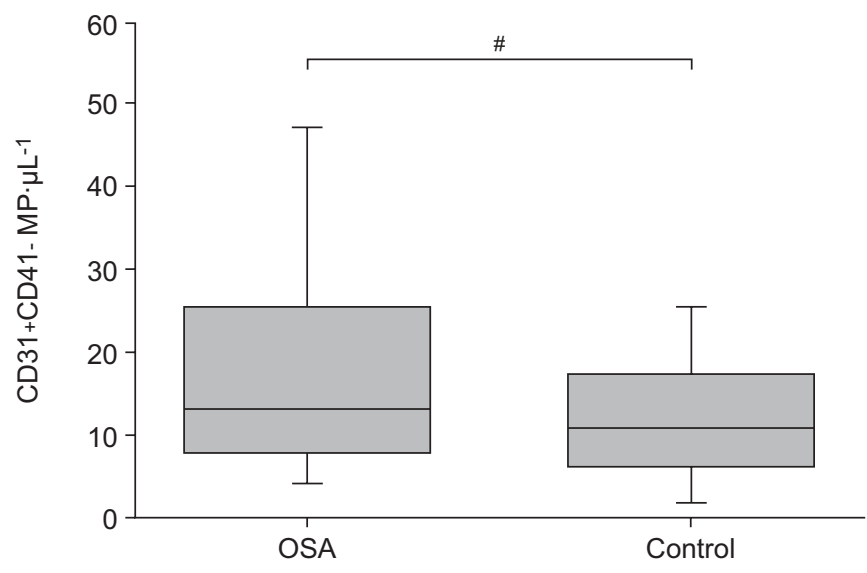

FIGURE 3. There was no significant difference between CD31+CD41endothelial cell-derived microparticle (MP) levels in patients with minimally symptomatic obstructive sleep apnoea (OSA) compared with the matched control group without OSA. Box and whisker plots represent medians, interquartile ranges and 10 th and 90 th percentiles. ${ }^{*}: \mathrm{p}=0.21$.

\section{CD45+ LMPs}

The median level of LMPs was significantly higher in patients with minimally symptomatic OSA $\left(20(14-31) \mu \mathrm{L}^{-1}\right)$ than in matched control subjects $\left(15(5-23) \mu \mathrm{L}^{-1} ; \mathrm{p}=0.02\right.$; fig. 4$)$. There was a statistically significant correlation between the level of LMPs and ODI $(\mathrm{r}=0.30, \mathrm{p}=0.01)$.

\section{DISCUSSION}

To the best of the current authors' knowledge, the present study is the first to look at circulating MPs originating from different cell types in patients with OSA. It was found that patients with minimally symptomatic OSA have higher blood levels of AnnexinV+ MPs, PMPs and LMPs when compared to a well-matched control group without OSA. Although levels of EMPs were slightly higher in patients with OSA compared with control subjects, this did not reach statistical significance.

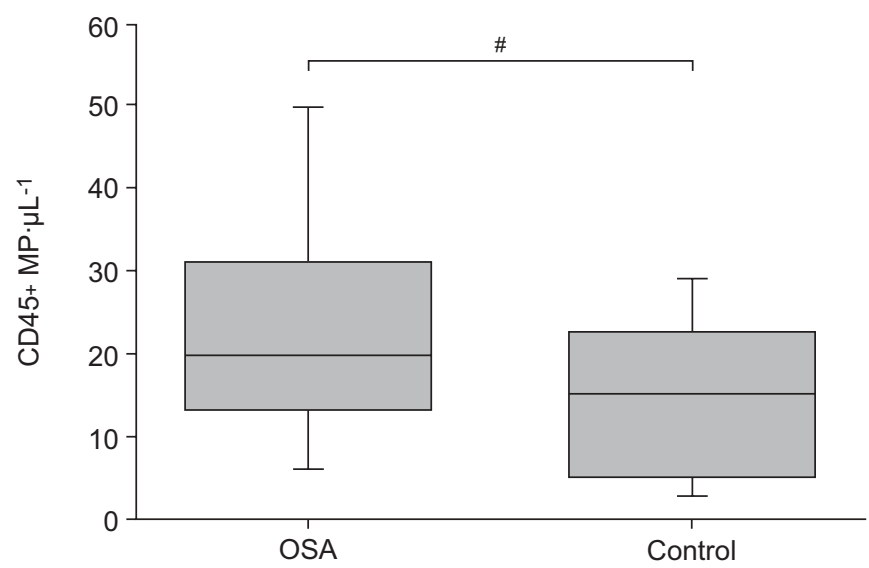

FIGURE 4. CD45+ lymphocyte-derived microparticle (MP) levels were significantly higher in patients with minimally symptomatic obstructive sleep apnoea (OSA) than in the control group without OSA. Box and whisker plots represent medians, interquartile ranges and 10th and 90th percentiles. ${ }^{*}: p=0.02$ 
There has been growing interest in circulating cell-derived MPs in recent years, as plasma levels of MPs have been shown to be elevated in patients with cardiovascular risk factors [9, 10], have been shown to predict subclinical atherosclerosis burden in asymptomatic subjects [11], and appear to be a predictor of the recurrence of myocardial infarction or death in patients with acute coronary syndromes [12]. Therefore, quantification of MPs seems to be a valuable tool for the exploration of cardiovascular risk in asymptomatic patients.

The finding that patients with minimally symptomatic OSA had twice the plasma level of AnnexinV+ MPs compared with closely matched control subjects without OSA (fig. 1) suggests that OSA could play an independent role in the formation of MPs. There are several possible links between OSA and the creation of MPs: platelets have been shown to release MPs after activation and in response to high vascular shear stress (e.g. during acute rises in blood pressure) [20], and endothelial cells and leukocytes release MP after activation by inflammatory cytokines (e.g. tumour necrosis factor- $\alpha$ ), aggregated lowdensity lipoproteins or reactive oxygen species [21, 22]. All of these mechanisms of MP formation have previously been shown to be associated with OSA [3, 23].

The present study found that levels of CD31+CD41+ PMPs were more than twice as high in OSA patients than in control subjects (fig. 2). This is in contrast to the report of GEISER et al. [24], who found no difference in PMP levels between 12 patients with moderate-severe OSAS and six healthy controls. Possible explanations for this negative finding may be the small sample size and the different technique used to detect PMPs in the study by GEISER et al. [24].

PMPs have been shown to have pro-thrombogenic and/or proatherogenic effects in experimental vascular models by enhancing monocyte arrest on activated endothelium through P-selectin, glycoprotein IIb/IIIa, RANTES (Regulated upon Activation, Normal T-cell Expressed, and Secreted) and intercellular adhesion molecule (ICAM)-1 [25, 26]. In addition, PMPs express CD40L, which has been shown to stabilise arterial thrombi [27]. As elevated levels of P-selectin, CD40L and ICAM-1 have been associated with OSA in previous reports [28, 29], the elevated PMP levels found in the present study may be a novel important link between these proatherogenic factors and OSA.

The two-fold elevation in PMP levels found in patients with OSA compared with the control group is comparable to the difference in PMP levels reported between patients with severe arterial hypertension and normotensive control subjects [9]. Therefore, it appears that the difference found in the present study may be of clinical importance.

OSA is considered to represent a pro-inflammatory state, as evidenced by increased levels of pro-inflammatory proteins and cytokines, and thereby leading to endothelial dysfunction and atherosclerosis [23]. The finding that LMP levels were higher in patients with minimally symptomatic OSA compared with control subjects (fig. 4) suggests that even minimally symptomatic OSA may be associated with systemic inflammation, as it has been shown that LMP formation is enhanced by inflammatory stimuli [30]; in turn, LMPs induce interleukin (IL)-6, IL-8 and monocyte chemotactic protein-1 production
[31]. The clinical significance of this finding is supported by a recently published study which reported that LMP levels predict subclinical atherosclerosis, as measured by plaque burden of carotid, abdominal aorta and femoral arteries in 216 asymptomatic patients without overt cardiovascular disease [11].

The level of EMPs has been shown to be an index of endothelial injury in patients with coronary artery disease and is possibly useful for identifying asymptomatic patients with diabetes mellitus at increased risk of coronary artery disease [32, 33]. Although levels of CD31+CD41- EMPs were slightly higher in patients with OSA compared with control subjects in the present study, this difference did not reach statistical significance (fig. 3). This in contrast to a report of EL SolH et al. [6], who found increased levels of apoptotic endothelial cells in 14 patients with moderate-severe OSA when compared with healthy control subjects. It must be mentioned that in the latter study the authors aimed to measure apoptotic circulating endothelial cells rather than EMPs (apoptotic endothelial cells are considerably larger than MPs), and the detection of endothelial cells in their study was based on a relatively nonspecific marker (CD146), which is also recognised on other cell lines such as tumour, smooth muscle, dendritic and stroma cells [34].

However, a possible explanation for the negative finding in the present study could be that patients with minimally symptomatic OSA may not yet have structural damage of endothelial cells and, therefore, do not produce high levels of CD31+CD41EMPs, which have been shown to reflect structural damage of endothelial cells rather than endothelial cell activation [35]. Therefore, in future studies looking at EMPs in patients with OSA, markers that are more specific for endothelial cell activation, such as CD62E+ EMP [35], should be analysed as well. Furthermore, the relatively small number of EMPs in the plasma might have reduced the power to detect a significant difference between patients with OSA and the control group.

At this point it must be mentioned that, although the OSA and control group were matched as closely as possible, it still remains possible that there are other unmeasured and important differences between the two groups that might account for the differences in MPs found. Possible evidence of this is that OSA patients had a larger neck circumference, despite identical BMI and waist-to-hip ratio. This may indicate a difference in fat distribution that, in turn, may reflect metabolic differences. Therefore, the present study can only generate the hypothesis that minimally symptomatic OSA could raise the cardiovascular risk and that this is reflected in elevated MP levels. Controlled interventional trials are needed to see if such changes are reversible before cause and effect can be implied.

Furthermore, the question of whether circulating levels of MPs represent a cause or simply a marker of vascular disease in patients with OSA remains unsolved. It is possible that intermittent hypoxia may directly induce cell apoptosis and thereby leads to elevated levels of MPs.

In conclusion, the present study found elevated levels of total, platelet-derived and leukocyte-derived microparticles in patients with minimally symptomatic obstructive sleep apnoea when compared to well-matched control subjects without 
obstructive sleep apnoea, although this was not associated with a significantly increased level of endothelial cell-derived microparticles. The elevated levels of microparticles that was found may provide an important link between obstructive sleep apnoea and pro-atherogenic mechanisms such as thrombosis, inflammation and endothelial dysfunction. The findings suggest that patients with minimally symptomatic obstructive sleep apnoea might have increased cardiovascular risk, but any cause and effect relationship has to be proven in randomised controlled interventional studies.

\section{REFERENCES}

1 Young T, Peppard PE, Gottlieb DJ. Epidemiology of obstructive sleep apnea: a population health perspective. Am J Respir Crit Care Med 2002; 165: 1217-1239.

2 Peker Y, Hedner J, Norum J, Kraiczi H, Carlson J. Increased incidence of cardiovascular disease in middle-aged men with obstructive sleep apnea: a 7-year follow-up. Am J Respir Crit Care Med 2002; 166: 159-165.

3 Somers VK, Kyken ME, Clary MP, Abbound FM. Sympathetic neural mechanisms in obstructive sleep apnea. J Clin Invest 1995; 96: 1897-1904.

4 Shamsuzzaman AS, Winnicki M, Lanfranchi P, et al. Elevated C-reactive protein in patients with obstructive sleep apnea. Circulation 2002; 105: 2462-2464.

5 Ip MSM, Tse HF, Lam B, Tsang KWT, Lam WK. Endothelial function in obstructive sleep apnea and response to treatment. Am J Respir Crit Care Med 2004; 169: 348-353.

6 El Solh AA, Akinnusi ME, Baddoura FH, Mankowski CR. Endothelial cell apoptosis in obstructive sleep apnea: a link to endothelial dysfunction. Am J Respir Crit Care Med 2007; 175: 1186-1191.

7 Hugel B, Martinez MC, Kunzelmann C, Freyssinet JM. Membrane microparticles: two sides of the coin. Physiology 2005; 20: 22-27.

8 Van Wijk M, Van Bavel E, Sturk A, Nieuwland R. MP in cardiovascular diseases. Cardiovasc Res 2003; 59: 277-287.

9 Preston RA, Jy W, Jimenez JJ, Mauro LM, Horstman LL, Valle M, Aime G, Ahn YS. Effects of severe hypertension on endothelial and platelet microparticles. Hypertension 2003; 41: 211-217.

10 Diamant M, Nieuwland R, Pablo RF, Sturk A, Smit JW, Radder JK. Elevated numbers of tissue-factor exposing microparticles correlate with components of the metabolic syndrome in uncomplicated type 2 diabtes mellitus. Circulation 2002; 106: 2442-2447.

11 Chironi G, Simon A, Hugel B, et al. Circulating leukocytederived microparticles predict subclinical atherosclerosis burden in asymptomatic subjects. Arterioscler Thromb Vasc Biol 2006; 26: 2775-2780.

12 Boulanger CM, Amabile N, Tedgui A. Circulating microparticles: a potential prognostic marker for atherosclerotic vascular disease. Hypertension 2006; 48: 180-186.

13 Pitson DJ, Stradling JR. Autonomic markers of arousal during sleep in patients undergoing investigation for obstructive sleep apnoea, their relationship to EEG arousals, respiratory events and subjective sleepiness. J Sleep Res 1998; 7: 53-60.
14 Argod J, Pepin JL, Levy P. Differentiating obstructive and central sleep respiratory events through pulse transit time. Am J Respir Crit Care Med 1998; 158: 1778-1783.

15 Wang Y, Teschler T, Weinreich G, Hess S, Wessendorf TE, Teschler $H$. Validation of microMESAM as screening device for sleep disordered breathing. Pneumologie 2003; 57: 734-740.

16 Johns MW. A new method for measuring daytime sleepiness: the Epworth sleepiness scale. Sleep 1991; 14: 540-545.

17 Bennett LS, Stradling JR, Davies RJ. A behavioural test to assess daytime sleepiness in obstructive sleep apnoea. J Sleep Res 1997; 6: 142-145.

18 Pocock SJ, McCormack V, Gueyffier F, Boutitie F, Fagard RH, Boissel JP. A score for predicting risk of death from cardiovascular disease in adults with raised blood pressure, based on individual patient data from randomised controlled trials. BMJ 2001; 323: 75-81.

19 Biro E, Nieuwland R, Sturk A. Measuring circulating cell-derived microparticles. J Thromb Haemost 2004; 2: 1843-1844.

20 Reininger AJ, Heijnen HF, Schumann H, Specht HM, Schramm W, Ruggeri ZM. Mechanism of platelet adhesion to von Willebrand factor and microparticle formation under high shear stress. Blood 2006; 107: 3537-3545.

21 Satta N, Toti F, Feugeas O, et al. Monocyte vesiculation is a possible mechanism for dissemination of membraneassociated procoagulant activities and adhesion molecules after stimulation by lipopolysaccharide. J Immunol 1994; 153: 3245-3255.

22 Patel KD, Zimmerman GA, Prescott SM, McIntyre TM. Novel leukocyte agonists are released by endothelial cells exposed to peroxide. J Biol Chem 1992; 267: 15168-15175.

23 Gozal D, Kheirandish-Gozal L. Cardiovascular morbidity in obstructive sleep apnea: oxidative stress, inflammation, and much more. Am J Respir Crit Care Med 2008; 177: 369-375.

24 Geiser T, Buck F, Meyer BJ, Bassetti C, Haeberli A, Gugger M. In vivo platelet activation is increased during sleep in patients with obstructive sleep apnea syndrome. Respiration 2002; 69: 229-234.

25 Mause SF, Von Hundelshausen P, Zernecke A, Koenen RR, Weber C. Platelet microparticles: a transcellular delivery system for RANTES promoting monocyte recruitment on endothelium. Arterioscler Thromb Vasc Biol 2005; 25: 1512-1518.

26 Schober A, Manka D, Von Hundelshausen P, et al. Deposition of platelet RANTES triggering monocyte recruitment requires $\mathrm{P}$-selectin and is involved in neointima formation after arterial injury. Circulation 2002; 106: 1523-1529.

27 Andre P, Prasad KS, Denis CV, et al. CD40L stabilizes arterial thrombi by a $\beta 3$ integrin-dependent mechanism. Nat Med 2002; 8: 247-252.

28 Minoguchi K, Yokoe T, Tazaki $\mathrm{T}$, et al. Silent brain infarction and platelet activation in obstructive sleep apnea. Am J Respir Crit Care Med 2007; 175: 612-617.

29 El-Solh AA, Mador MJ, Sikka P, Dhillon RS, Amsterdam D, Grant BJ. Adhesion molecules in patients with coronary artery disease and moderate-to-severe obstructive sleep apnea. Chest 2002; 121: 1541-1547. 
30 Mesri M, Altieri DC. Endothelial cell activation by leukocyte microparticles. J Immunol 1998; 161: 4382-4387.

31 Mesri M, Altieri DC. Leukocyte microparticles stimulate endothelial cell cytokine release and tissue factor induction in a JNK1 signaling pathway. J Biol Chem 1999; 274: 23111-23118.

32 Koga H, Sugiyama S, Kugiyama K, et al. Elevated levels of VE-cadherin-positive endothelial microparticles in patients with type 2 diabetes mellitus and coronary artery disease. J Am Coll Cardiol 2005; 45: 1622-1630.
33 Boulanger CM, Scoazec A, Ebrahimian T, et al. Circulating microparticles from patients with myocardial infarction cause endothelial dysfunction. Circulation 2001; 104: 2649-2652.

34 Bardin N, George F, Mutin M, et al. S-endo 1, a panendothelial monoclonal antibody recognizing a novel human endothelial antigen. Tissue Antigens 1996; 48: 531-539.

35 Jimenez JJ, Jy W, Mauro LM, Soderland C, Horstman LL, Ahn YS. Endothelial cells release phenotypically and quantitatively distinct microparticles in activation and apoptosis. Thromb Res 2003; 109: 175-180. 